\title{
AVALIAÇÃO DA FITOTOXICIDADE DE EFLUENTE TÊXIL CONTENDO CORANTE CI REACTIVE BLUE 222 APÓS O TRATAMENTO POR PLEUROTUS OSTREATUS EM BIORREATOR.
}

\author{
F. C. BELLATO ${ }^{1}$, G. O. F. SANTOS ${ }^{2}$, J. M. ROSA ${ }^{3}$, D. R. MATHEUS ${ }^{4}$ \\ ${ }^{1,4}$ Fundação Universidade Federal do ABC \\ 2 Universidade de São Paulo \\ ${ }^{3}$ FEQ - UNICAMP; Faculdade de Tecnologia SENAI Antoine Skaf \\ E-mail para contato: filipecbellato@hotmail.com
}

\begin{abstract}
RESUMO - O setor têxtil é de grande importância para a economia do Brasil, contudo, o efluente gerado por este ramo contém corantes de difícil remoção, podendo causar danos à saúde da população. Neste cenário, a busca por novas tecnologias se faz necessária e pode-se destacar a utilização de fungos basidiomicetos como uma alternativa eficiente e acessível. Diante disso, foi feito tratamento de efluente azul em biorreator com Pleurotus ostreatus. Desta maneira, o estudo da toxicidade deste efluente após o processo de tratamento pode ser feito a partir de testes de fitotoxicidade por Lactuca sativa (alface) e Sorghum sudanense (sorgo), por ser um método eficiente e barato. Os resultados apontam que o processo de tratamento fúngico de efluente contendo corante azul em biorreator foi satisfatório com relação a diminuição da toxicidade. Além disso, as sementes de alface e sorgo se apresentaram como um ótimo parâmetro por conta de sua sensibilidade diante do corante.
\end{abstract}

\section{INTRODUÇÃO}

O setor têxtil no Brasil colabora com a geração de aproximadamente 1,7 milhão de empregos diretos e um faturamento total de US\$ 56,7 bilhões (ABIT, 2012), porém, este setor também é responsável por diversos impactos ambientais, tal como a geração de efluentes provenientes dos seus processos industriais, que contêm altas concentrações de matéria orgânica, além da presença de corantes de difícil remoção (BASTIAN et al., 2009).

Quando não tratados adequadamente antes de serem lançados em águas naturais, os efluentes contendo corantes podem modificar o ecossistema ou atingir a saúde da população. Os riscos para a saúde humana variam de acordo com a forma e o tempo de exposição ao corante, podendo provocar dermatites e problemas respiratórios, e em casos mais graves, por meio de biotransformações catalisadas por enzimas específicas, podem gerar substâncias com propriedades carcinogênicas e mutagênicas, como aminas aromáticas, toluidinas, benzidinas, 
radicais ativos, entre outras. Há indícios de associação de alguns corantes ao câncer de bexiga e do fígado em humanos, e anomalias nucleares e aberrações cromossômicas em animais (ZANONI e CARNEIRO, 2001).

Há técnicas diversas para o tratamento, sendo que as alternativas mais promissoras derivam do estudo de novas tecnologias. Neste panorama, os processos biológicos apresentam um grande potencial e interesse, por representarem uma solução eficiente e de custo mais acessível. Visto que os processos biológicos tradicionais não alcançam eficiência considerável na remoção de cor, outros organismos como fungos de decomposição branca (basidiomicetos) vêm sendo estudados (KUNZ et al., 2002).

O metabolismo desses compostos pelos basidiomicetos é consequência do mecanismo usado por estes organismos para degradar a lignina: processo multienzimático resultante da ação coordenada de uma série de enzimas oxidorredutases, intra e extracelulares, e de metabólitos de baixa massa molecular (DURÁN \& ESPOSITO, 2000; RABINOVICH et al., 2004).

A toxicidade originada do lançamento de efluentes em corpos receptores constitui-se como outro fator importante para estudo de pesquisadores e ambientalistas. Efluentes tratados, que atendam aos limites colocados pela legislação podem ainda apresentar toxicidade, uma vez que esta é resultado da interação de todos os constituintes do efluente e não somente dos parâmetros analisados (ARENZON et al., 2011). Em alguns países, os testes biológicos de toxicidade aguda já são obrigatórios para descarga de efluentes. Testes de ecotoxicidade medem a resposta produzida pela exposição a uma concentração específica de uma substância, comparado a um controle que não sofreu exposição (RUDNIK, 2008).

Dentre os testes biológicos empregados o uso de organismos vegetais (plantas) vem ganhando destaque, devido ao seu baixo custo e facilidade de operação e aplicação. A fitotoxicidade é expressa como atraso na germinação de sementes, inibição do crescimento da planta ou qualquer outra adversidade causada na planta, provocada por substância específica. Os testes de fitotoxicidade realizados em plantas terrestres recomendadas pela OECD (Organização para a Cooperação Econômica e Desenvolvimento) podem ser realizados em monocotiledôneas (arroz, aveia, azevém, trigo e sorgo) e dicotiledôneas (agrião, alface, feijão, nabo, rabanete, entre outras) (RUDNIK, 2008).

Nestas circunstâncias, propõe-se a avaliação da fitotoxicidade de efluentes do banho de tingimento da indústria têxtil, contendo os corantes azul, antes e após o tratamento por fungos basidiomicetos em biorreator, por duas espécies vegetais: a dicotiledônea Lactuca sativa (alface) e a monocotiledônea Sorghum sudanense (sorgo).

\section{METODOLOGIA}

Os fungos foram imobilizados em bucha vegetal (Luffa cylindrica), previamente esterilizada junto ao biorreator. Cada sistema foi composto por aproximadamente $52 \mathrm{~g}$ de bucha cortada, submersa em $4 \mathrm{~L}$ de meio líquido basal $(9,0 \mathrm{~g}$ de sacarose, $0,506 \mathrm{~g}$ de uréia, 0,2 $\mathrm{g}$ de $\mathrm{KH}_{2} \mathrm{PO} 4,0,05 \mathrm{~g}$ de $\mathrm{MgSO}_{4} .7 \mathrm{H}_{2} \mathrm{O}, 0,016 \mathrm{~g}$ de $\mathrm{MnSO}_{4} . \mathrm{H}_{2} \mathrm{O}$ e $0,049 \mathrm{~g}$ de $\mathrm{CuSO}_{4} .5 \mathrm{H}_{2} \mathrm{O}$ por litro) por $48 \mathrm{~h}$, e posteriormente drenado. Formou-se um sobrenadante correspondendo a biomassa fúngica resultado do crescimento em meio líquido batata dextrose (BD) por 7 dias 
em vinte e um erlenmeyers de aproximadamente $60 \mathrm{~mm}^{2}$. Esta biomassa foi processada em blender, diluídos em 4L de meio líquido basal, agitados a 180 RPM durante $1 \mathrm{~h}$ no biorreator e posteriormente drenado e incubado por 10 dias, à temperatura de $25 \pm 2^{\circ} \mathrm{C}$ sem agitação.

Após o período de incubação foi introduzido $5 \mathrm{~L}$ de efluente adicionado dos componentes do meio descritos anteriormente, diluídos no próprio efluente. $\mathrm{O} p \mathrm{H}$ foi ajustado para um valor de 7,0 $\pm 0,8$ durante o período de contato do fungo $(24 \mathrm{~h})$ com o efluente. O sistema foi mantido a $25 \pm 2{ }^{\circ} \mathrm{C}$ com agitação de 40 RPM.

A análise da fitotoxicidade consistiu na coleta do efluente antes do tratamento, e após o tratamento fúngico. Os testes ocorreram em condições estáticas tendo como base as metodologias descritas por Tam e Tiquia (1994) e Andrade (2009), com as devidas adaptações, consistindo em colocar 20 sementes de cada espécie vegetal sobre papel de filtro Whatman n.40 em placas de Petri com $2 \mathrm{~mL}$ (para alface) e $3 \mathrm{~mL}$ (para sorgo) de cada diluição da amostra de uma série geométrica $(100 ; 50 ; 25 ; 12,5$ e 6,25\%). Água destilada está sendo utilizada como controle negativo (representando $0 \%$ do efluente). As amostras foram incubadas no escuro, envoltas em papel de alumínio, com temperatura controlada de $25 \pm 2$ ${ }^{\circ} \mathrm{C}$. O tempo total de duração do teste foi de $120 \mathrm{~h}$ e o número de sementes que germinaram após o período de incubação é contado e o comprimento das raízes (do ponto de transição entre o hipocólito e a raiz, até a extremidade da raiz) medido.

O índice de germinação (IG) é calculado combinando o percentual de germinação de sementes e a medida de crescimento das raízes, de acordo com as seguintes equações:

Germinação Relativa (GR):

$$
G R(\%)=\left(\frac{N E}{N C}\right) \times 100
$$

- $\mathrm{NE}=$ número de sementes que germinaram na amostra de efluente;

- $\quad \mathrm{NC}=$ número de sementes que germinaram no controle;

Crescimento Relativo das Raízes (CRR):

$$
\operatorname{CRR}(\%)=\left(\frac{M E}{M C}\right) \times 100
$$

- $\quad M E=$ média do crescimento das raízes na amostra de efluente;

- $\quad M C=$ média do crescimento das raízes no controle;

Índice de Germinação (IG): 


$$
I G(\%)=\frac{[G R(\%) \times C R R(\%)]}{100}
$$

\section{RESULTADOS E DISCUSSÃO}

Os resultados obtidos estão evidenciados na Tabela 1 e nos Gráficos 1 e 2.

Tabela 1: Valores de índice de germinação (IG \%) de sementes de alface e sorgo em amostras de efluente têxtil. Os sistemas contendo as sementes foram, separadamente, submetidos a cinco concentrações diferentes de efluente $(6,25 \% ; 12,5 \% ; 25 \%, 50$ e $100 \%)$ mais o controle com água destilada. $\mathrm{O}$ teste foi feita em duplicata, antes e após o tratamento em biorreator.

\begin{tabular}{|c|c|c|c|c|}
\cline { 2 - 5 } \multicolumn{1}{c|}{} & \multicolumn{4}{c|}{ Índice de Germinação (IG\%) } \\
\cline { 2 - 5 } \multicolumn{1}{c|}{} & \multicolumn{3}{c|}{ Bruto } & Tratado em biorreator \\
\hline \multirow{2}{*}{ Diluições } & Sorgo & Alface & Sorgo & Alface \\
\hline \multirow{2}{*}{$6,25 \%$} & 6,488 & 0 & 58,509 & 1,029 \\
& 5,219 & 0 & 61,912 & 0,000 \\
\hline \multirow{2}{*}{$12,5 \%$} & 48,096 & 0 & 62,074 & 77,029 \\
& 61,918 & 0 & 104,214 & 69,001 \\
\hline \multirow{2}{*}{$25 \%$} & 67,842 & 52,663 & 79,903 & 114,933 \\
& 57,969 & 25,126 & 61,102 & 94,748 \\
\hline \multirow{2}{*}{$50 \%$} & 95,345 & 117,588 & 85,575 & 102,163 \\
& 94,076 & 135,276 & 109,238 & 104,634 \\
\hline \multirow{2}{*}{$100 \%$} & 104,372 & 127,437 & 97,569 & 103,810 \\
& 99,295 & 127,839 & 72,933 & 105,253 \\
\hline
\end{tabular}




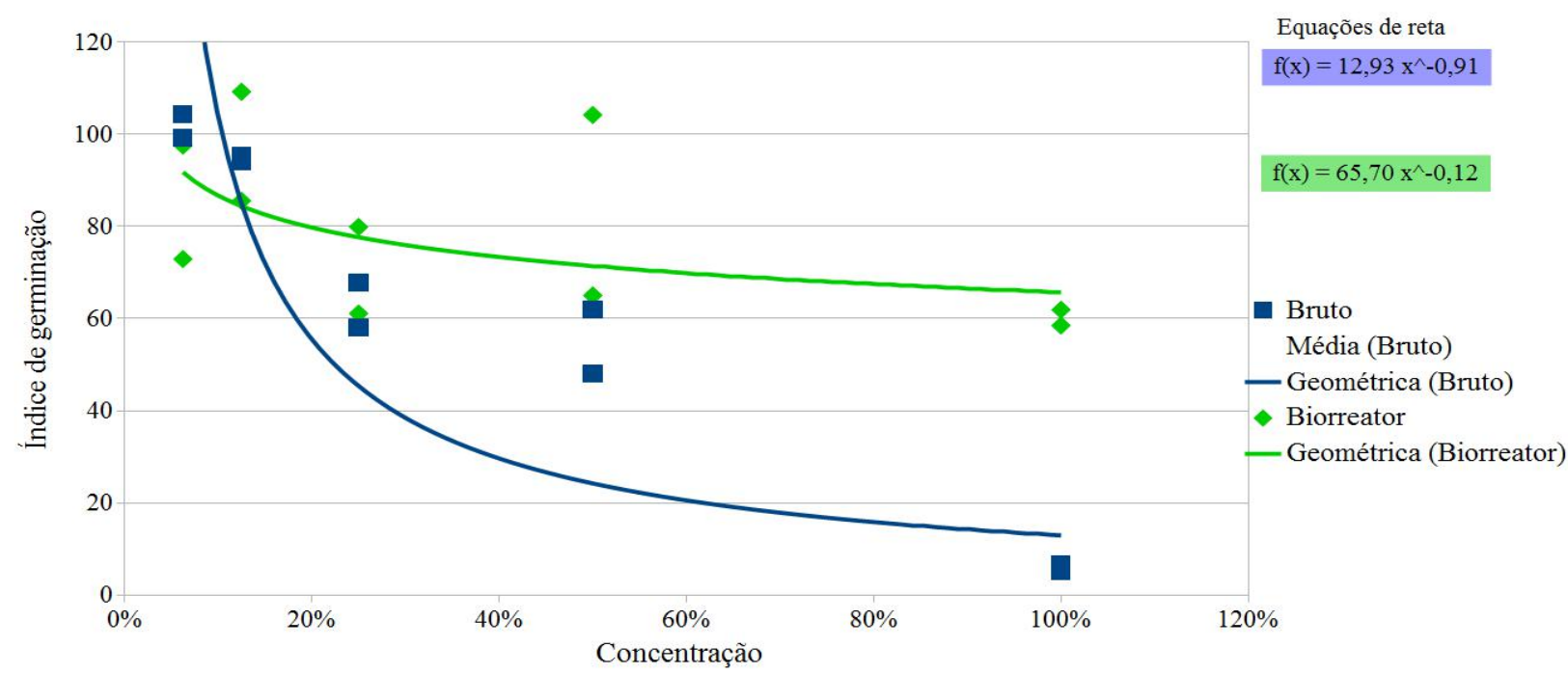

Gráfico 2: Comparação entre valores obtidos nos testes de fitotoxicidade em alface para o Corante C.I. Reactive Blue 222

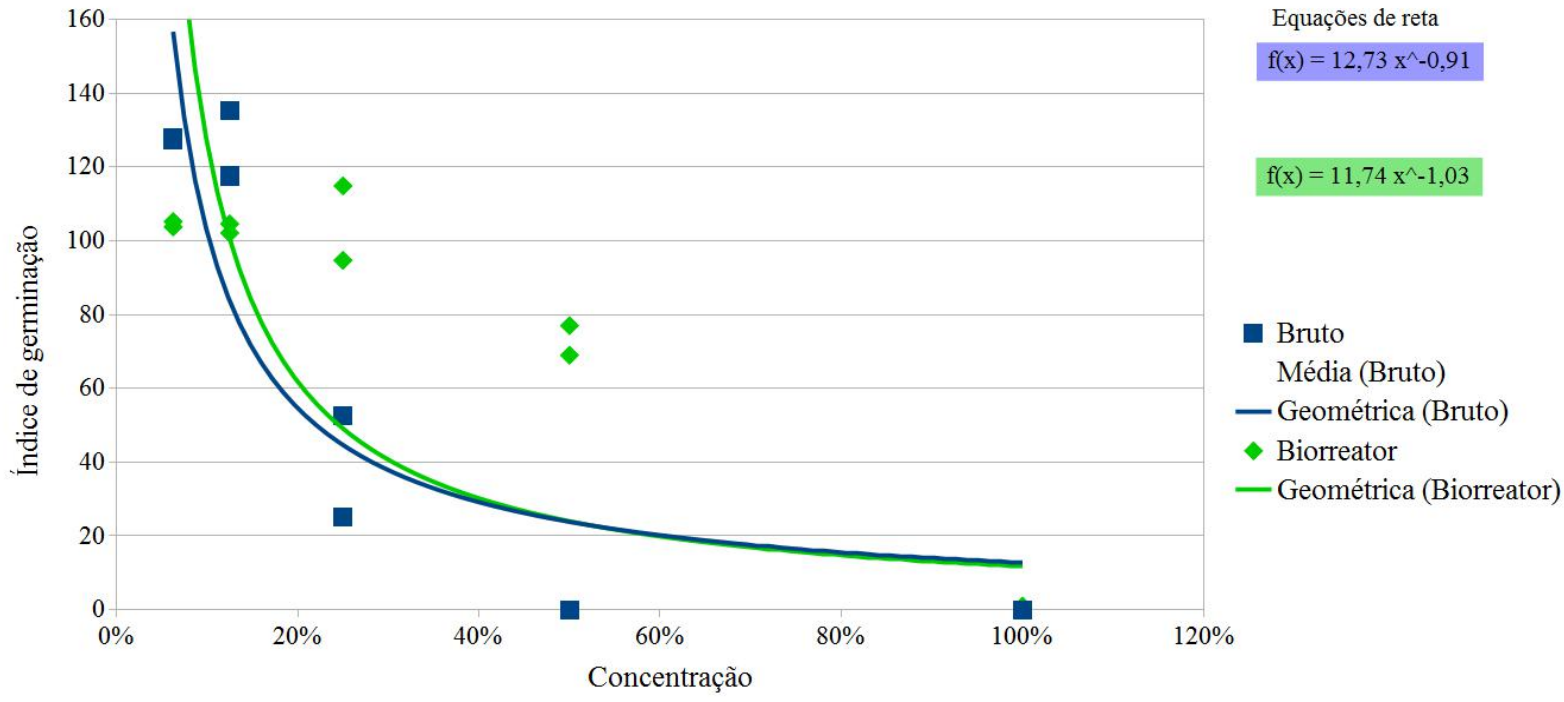

No caso do corante azul, ambos testes proporcionaram a observação de que as amostras após o tratamento fúngico tiveram uma diminuição da toxicidade do efluente sendo mais evidente nos testes com sorgo.

Dessa maneira, é possível observar que os valores obtidos para alface e sorgo após o tratamento são bastante distintos, diferentemente dos testes antes do tratamento. O gráfico de 


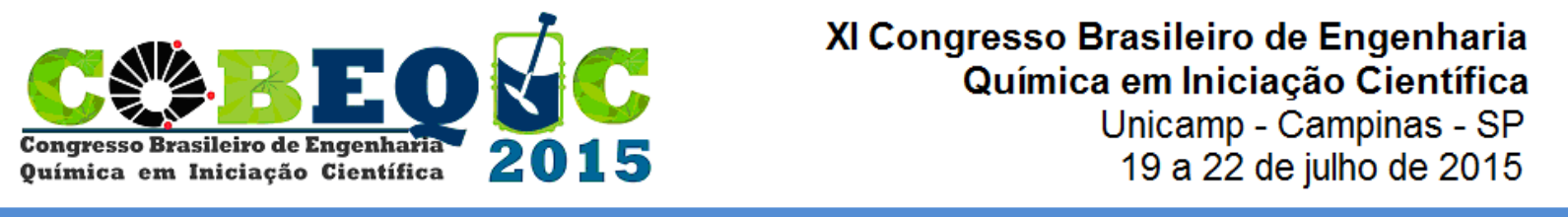

sorgo apresentou uma característica mais próxima da linearidade enquanto o de alface ainda possui característica geométrica.

Além disso, a sensibilidade de alface para efluentes com corantes é bastante similar ao que foi relatado nos estudos de água de processo evaporativo por Andrade (2009) e também na toxicidade de estrume de porco por Tam e Tiquia (1994) na qual os resultados indicaram altas taxas de germinação das sementes e sensibilidade no alongamento das raízes e dessa maneira, sendo considerado como uma espécie favorável e apropriada para os testes detoxicidade aguda.

\section{CONCLUSÃO}

Os dados indicam que a fitotoxicidade mostra-se como uma ferramenta satisfatória, devido a sua acessibilidade e baixo custo. Além disso, o sorgo presenta dados preliminares que são promissores para o atual estudo. Desta maneira, se faz necessário o desenvolvimento de estudos para qualificar os dados o de sensibilidade de toxicidade em sorgo.

\section{REFERÊNCIAS BIBLIOGRÁFICAS}

ANDRADE, V. T. Avaliação da toxicidade de água produzida tratada por processo evaporativo com a finalidade de reúso em solo. 2009. 164f. Tese (Doutorado em Engenharia Química) - Universidade Federal do Rio de Janeiro, Rio de Janeiro, 2009.

ASSOCIAÇÃO BRASILEIRA DE INDÚSTRIA TÊXTIL (ABIT). Disponível em: <http: www.abit.org.br>.

ARENZON, A.; PEREIRA NETO, T. J.; GERBER, W. Manual sobre toxicidade de efluentes têxteis, CEP Senai de Artes Gráficas Henrique D’Ávila Bertaso, Porto Alegre, 2011.

BASTIAN, E. Y. O.; ROCCO, J. L. S.; MARTIN, E. S. Guia Técnico Ambiental da Indústria Têxtil . São Paulo, CETESB - SINDITÊXTIL, 2009.

DURÁN, N.; ESPOSITO, E. Potential applications of oxidative enzymes and phenoloxidaselike compounds in wastewater and soil treatment: a review. Applied Catalysis B: Environmental, v. 28, n. 2, p. 83-99, 2000.

KUNZ, A; PERALTA-ZAMORA, P.; MORAES, S. G.; DURÁN, N. Novas tendências no tratamento de efluentes têxteis. Quimica Nova, v. 25, n. 1, p. 78-82, 2002. 
RABINOVICH, M. L.; BOLOBOVA, A. V.; VASIL'CHENKO, L. G. Fungal decomposition of natural aromatic structures and xenobiotics: A review. Applied Biochemistry and Microbiology, v. 40, n. 1, p. 1-17, 2004.

RUDNIK, E. Compostable Polymer Materials , Elsevier, Oxford, 2008.

TAM, N.F.Y.; TIQUIA, S.M. Assessing toxicity of spent sawdust pig-litter using seed germination technique. Resource Conservation Recycling, v.11, p.261-274, 1994.

ZANONI, M. V. B.; CARNEIRO, P. A. O descarte dos corantes têxteis. Ciência Hoje, v. 29, n. 174, p. 61-64, 2001. 